\title{
Ultrahigh-loading of Ir single atoms on NiO matrix to dramatically enhance oxygen evolution reaction
}

Qi Wang ${ }^{\# 1,4}$, Xiang Huang ${ }^{\sharp 2}$, Zhi Liang Zhao ${ }^{\# 1}$, Maoyu $\mathrm{Wang}^{3}$, Bin Xiang ${ }^{4}, \operatorname{Jun} \operatorname{Li}(\text { 李隽 })^{5}$, Zhenxing Feng*3, $\mathrm{Hu} \mathrm{Xu}^{* 2}$, Meng Gu*1

${ }^{1}$ Department of Materials Science and Engineering, and ${ }^{2}$ Department of Physics, Southern University of Science and Technology, Shenzhen 518055, China

${ }^{3}$ School of Chemical, Biological and Environment Engineering, Oregon State University, Oregon 97331, United States

${ }^{4}$ Department of Materials Science \& Engineering, University of Science and Technology of China, Hefei 230026, PR China

${ }^{5}$ Department of Chemistry Southern University of Science and Technology, Shenzhen 518055, China

\section{Content}

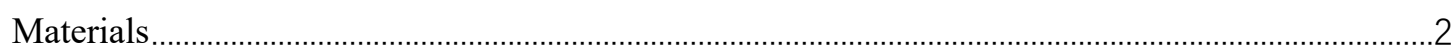

1. Additional electron microscope characterization ...........................................................................

1.1 SEM images of different magnification ...........................................................................

1.2 STEM images of different Ir loading ...........................................................................

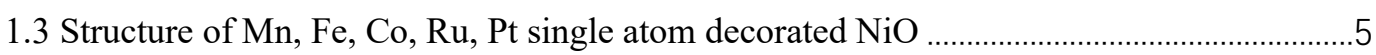

1.4 Structure of Ir-NiO after electrochemical test .......................................................................

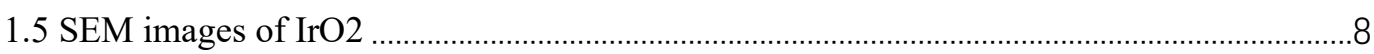

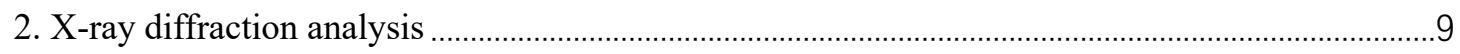

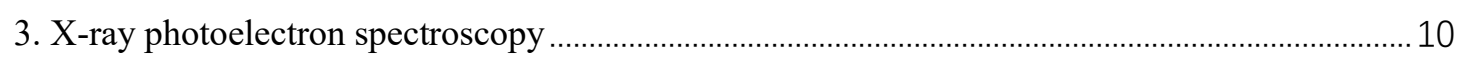

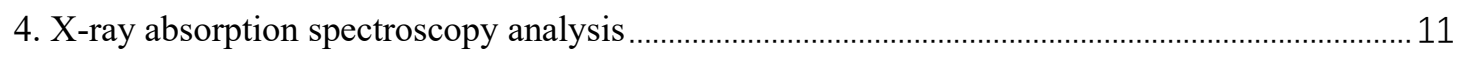

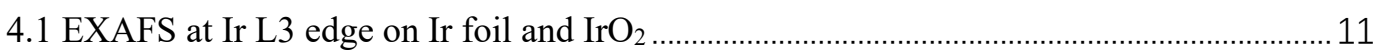

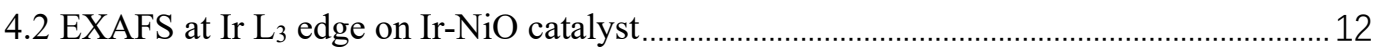

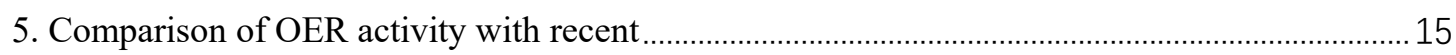

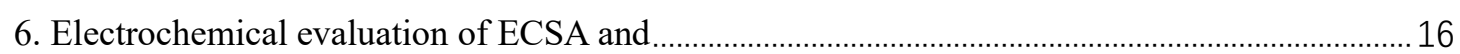

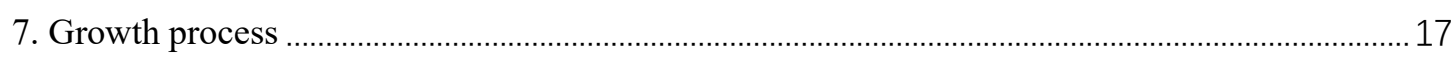

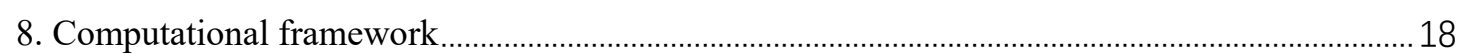

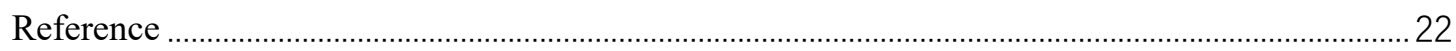




\section{Materials and methods}

Hexamethylenetetramine $(\geqslant 99.5 \%)$, Nickel nitrate hexahydrate $\left(\mathrm{Ni}\left(\mathrm{NO}_{3}\right)_{2} \cdot 6 \mathrm{H}_{2} \mathrm{O}, 99 \%\right)$ and Hexachloroiridium Acid Hydrate $\left(\mathrm{H}_{2} \mathrm{IrCl}_{6} \cdot \mathrm{xH}_{2} \mathrm{O}\right)$ were purchased from Aladdin without further purified. The commercial $\mathrm{IrO}_{2}(99.9 \%)$ was purchased from Sunlaite as reference catalyst

\section{Surface Area and Turnover frequency (TOF) calculation}

The surface areas of the films were estimated by measuring the electrochemical capacitance of the film-electrolyte interface in the double-layer regime of the voltammograms.

$$
\text { ECSA of the electrode }=\frac{\mathrm{C}_{\mathrm{dl}}}{\mathrm{Cs}}
$$

the specific capacitance $(C \mathrm{~s})$ we used here is $40 \mu \mathrm{F} \cdot \mathrm{cm}^{-2}$.

The TOF value is calculated from the following equation:

$$
\mathrm{TOF}=\mathrm{jA} / \mathrm{zFn}
$$

where $\mathrm{j}\left(\mathrm{A} \mathrm{cm}^{-2}\right)$ is current density at overpotential of $300 \mathrm{mV}$,

$A$ is working area of electrode,

$\mathrm{z}$ is electron transfer number per molecule generated,

F is Faraday constant $\left(96,500 \mathrm{C} \mathrm{mol}^{-1}\right)$ and $\mathrm{n}(\mathrm{mol})$ is total amount of $\mathrm{Ir}$ atoms and $\mathrm{Ni}$ atoms.

The $n$ was estimated by taking the measured surface area of the electrode and computing the number of $\mathrm{Ni}$ and $\mathrm{Ir}$ atoms at the surface using a value of $6.4 \times 10^{14}$ atoms per $\mathrm{cm}^{2}$ area. ${ }^{1}$ 


\section{Additional electron microscope characterization}

\subsection{SEM images of different magnification}

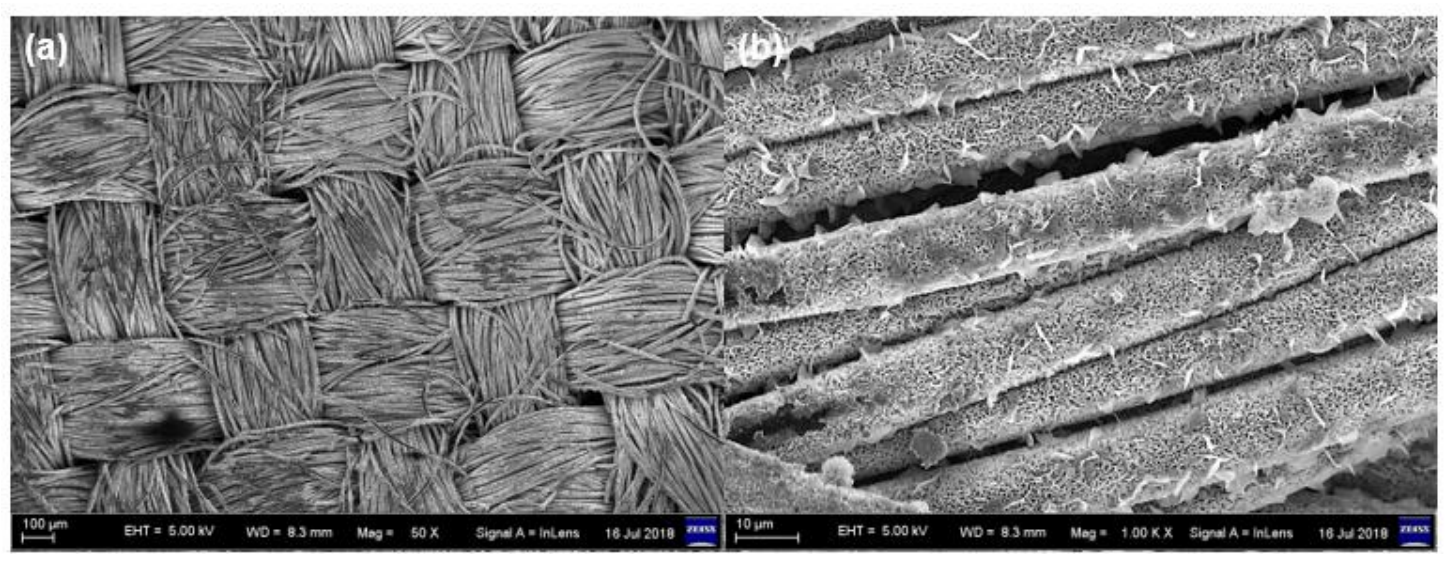

Figure S1 SEM images of carbon cloth supported Ir-NiO electrode in (a) low and (b) higher magnification 


\subsection{STEM images of different Ir loading}

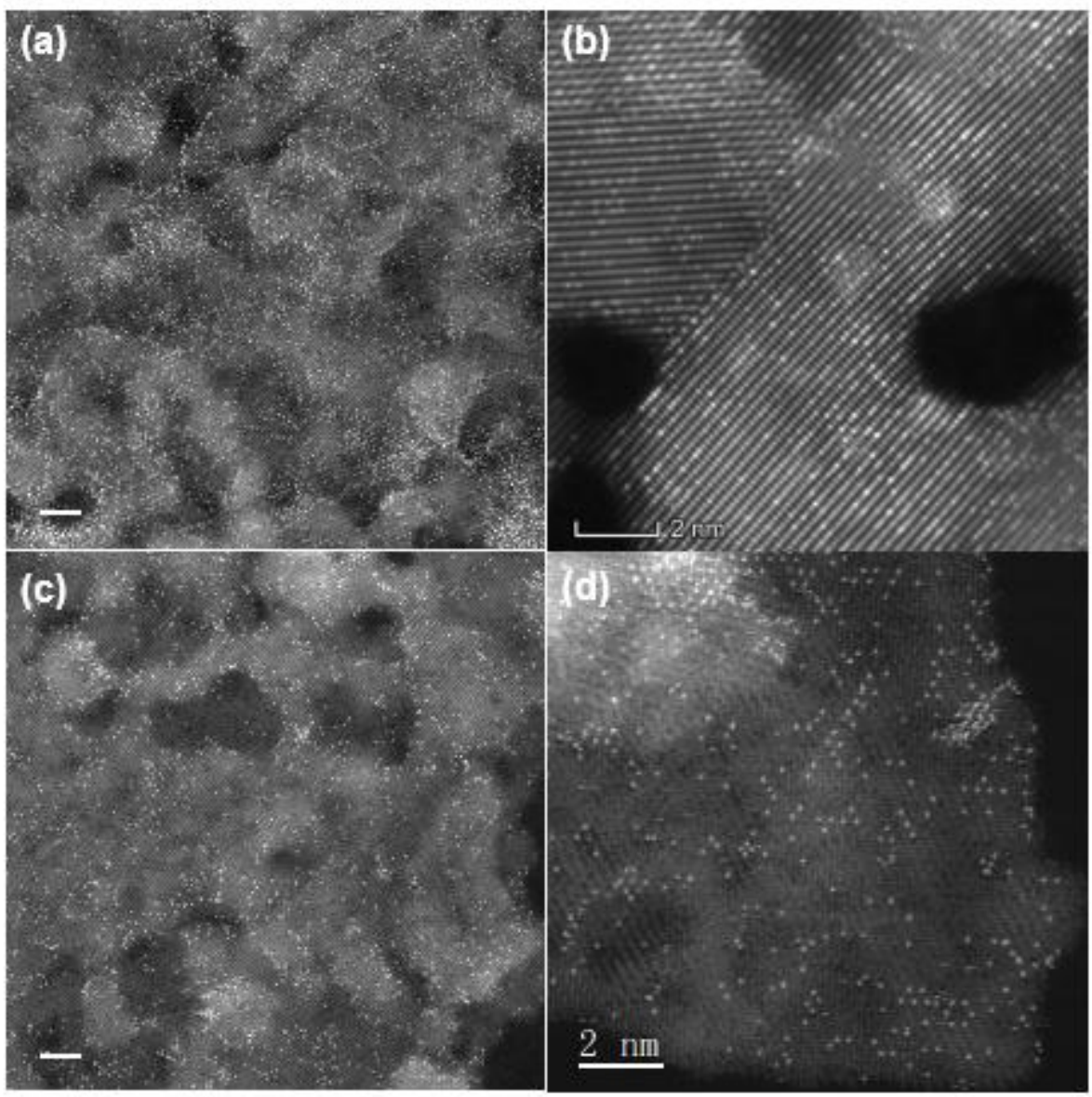

Figure S2 STEM images of (a-b) $\operatorname{Ir}_{11 \mathrm{wt} \%}-\mathrm{NiO}$ and (c-d) $\mathrm{Ir}_{2 \mathrm{wt} \%}-\mathrm{NiO}$. It can be seen the density of Ir are relatively sparser than $\operatorname{Ir}_{18 \mathrm{w} t \%}-\mathrm{NiO}$ samples. 


\subsection{Structure of $\mathrm{Mn}, \mathrm{Fe}, \mathrm{Co}, \mathrm{Ru}, \mathrm{Pt}$ single atom decorated $\mathrm{NiO}$}

Some other single atoms were obtained using the method in this work, including $\mathrm{Mn}, \mathrm{Fe}, \mathrm{Co}, \mathrm{Ru}$, Pt.

\subsubsection{Structure of Pt-NiO and Ru-NiO}

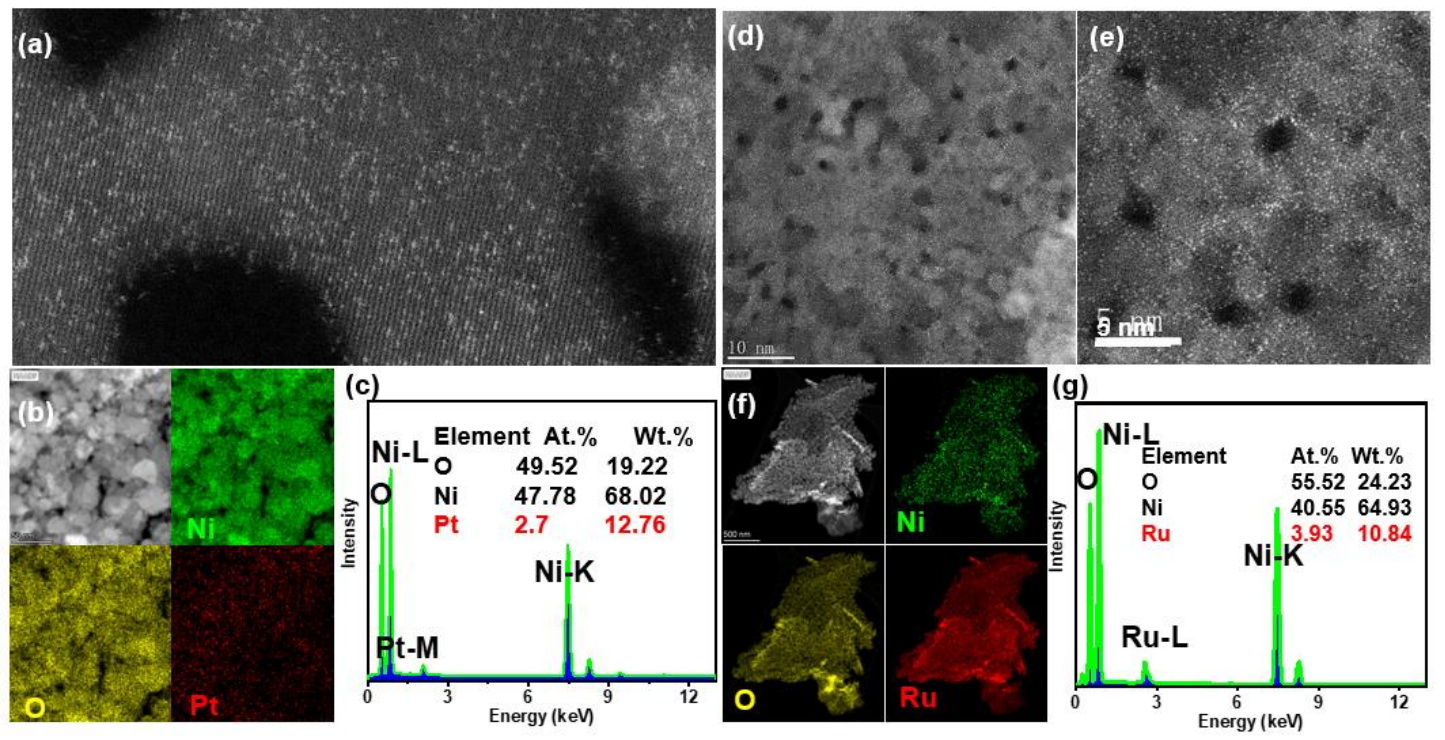

Figure S3 (a) Representative high magnification HAADF-STEM images indicating high density of Pt single atoms. (b) STEM-EDS elemental mapping and (c) corresponding EDS spectrum of PtNiO. (d) Representative low and (e) high magnification of HAADF-STEM images indicating high density Ru single atoms. (f) STEM-EDS elemental mapping and (g) corresponding EDS spectrum of Ru-NiO. 


\subsubsection{Structure of $\mathrm{Mn}-\mathrm{NiO}$ and $\mathrm{Co}-\mathrm{NiO}$,}

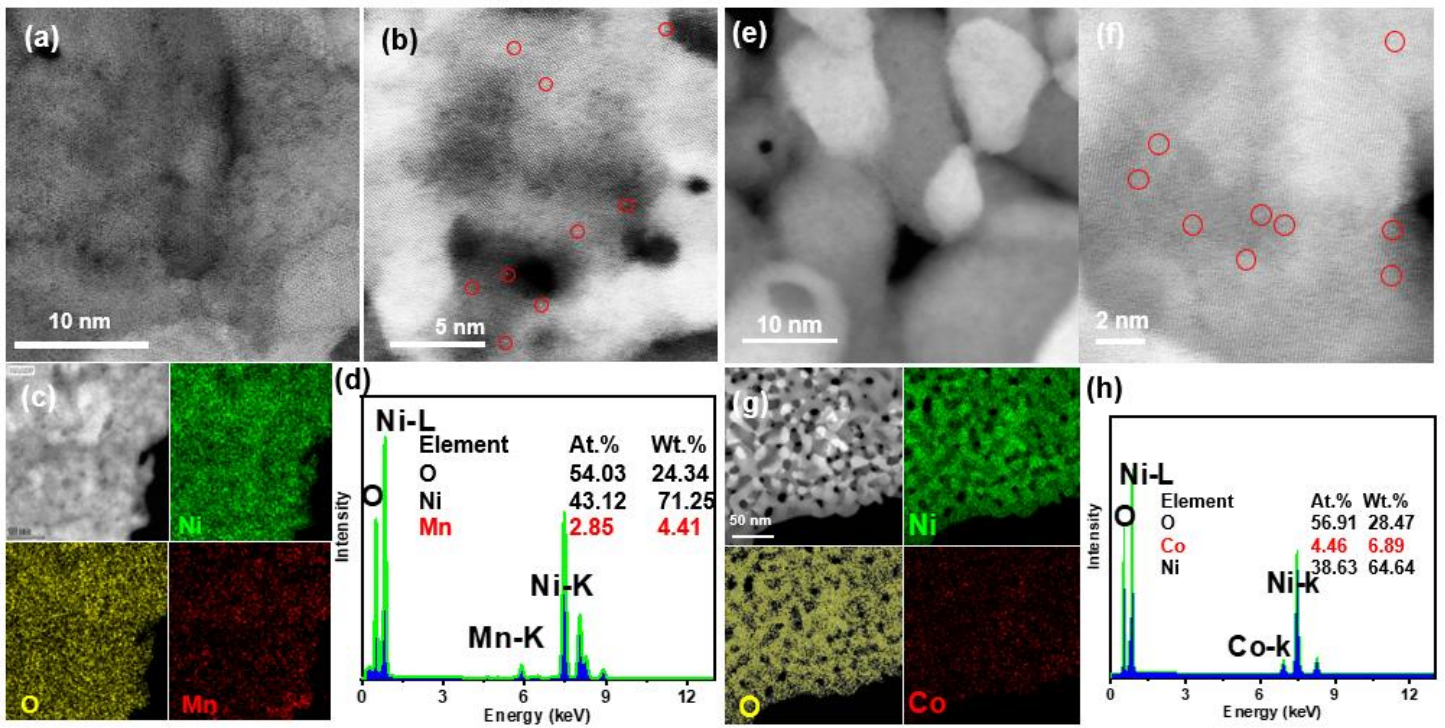

Figure S4 (a) Representative low and (b) high magnification HAADF-STEM images indicating high density of Mn single atoms. (c) STEM-EDS elemental mapping and (d) corresponding EDS spectrum of Mn-NiO. (e) Representative low and (f) high magnification of HAADF-STEM images indicating high density Co single atoms. (g) STEM-EDS elemental mapping and (h) corresponding EDS spectrum of Co-NiO.

\subsubsection{Structure of Fe-NiO}
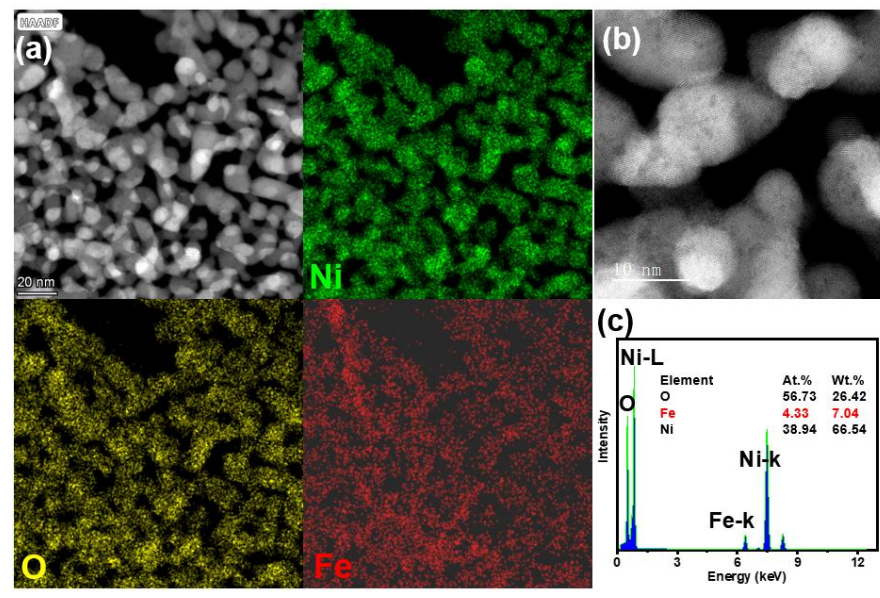

Figure S5 (a) STEM-EDS elemental mapping of Fe-NiO. (b) Representative high magnification HAADF-STEM images. (c) corresponding EDS spectrum of Fe-NiO. 


\subsection{Structure of Ir-NiO after electrochemical test}
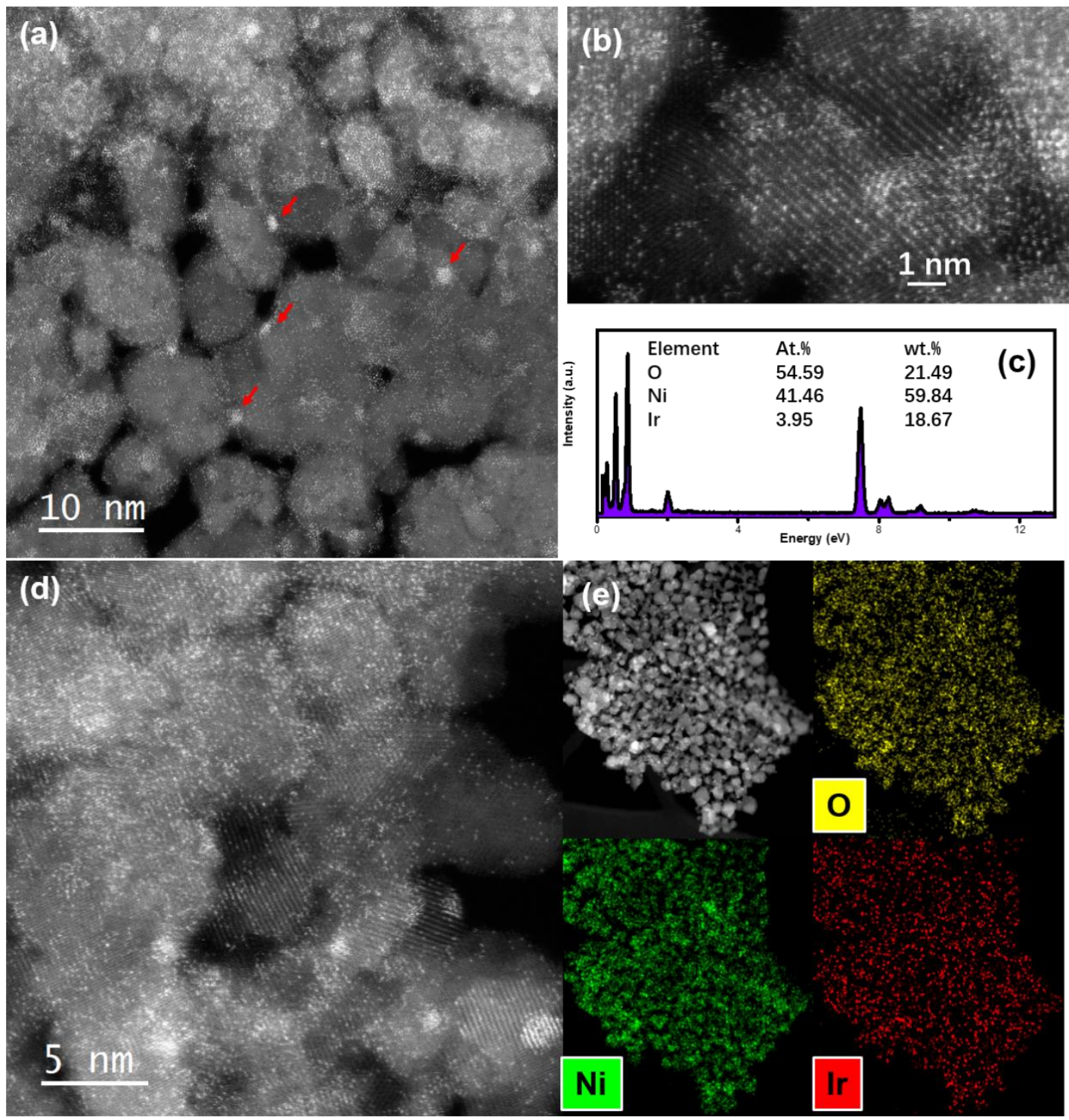

Figure S6 After i-t test for about 10 hours, the electrode was collected and studied with STEM to reveal the structure evolution during electrochemical test. ( $a, b$ and d) HAADF-STEM images of $\mathrm{Ir}_{18 \mathrm{wt} \%}-\mathrm{NiO}$ sample. Some small cluster with an average size of $1.1 \pm 0.1 \mathrm{~nm}$ were observed. Notwithstanding, most Ir atoms still isolated dispersed on $\mathrm{NiO}$, indicating the SA can stably maintain on the support. (c) The EDS spectrum revealed the wt. $\%$ of Ir to be $\sim 18 \%$ and(d) the EDS mapping indicated the evenly distribution of Ir. 


\subsection{SEM images of IrO2}

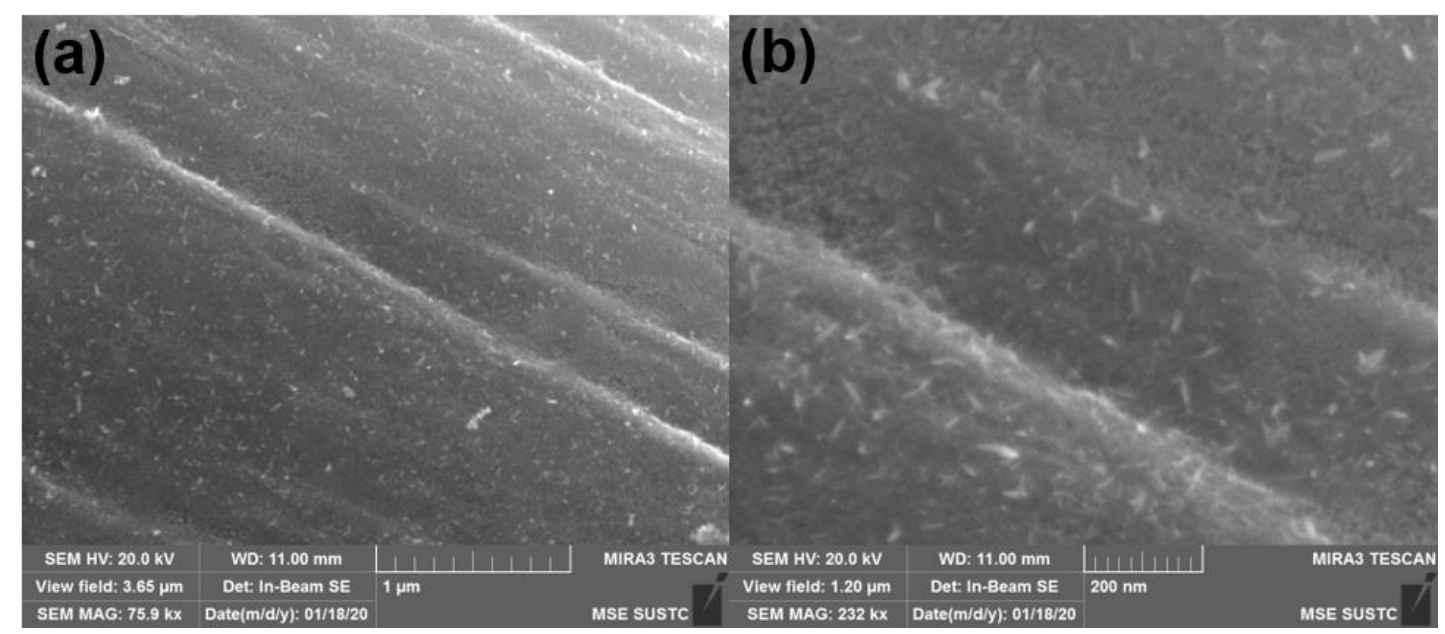

Figure S7 SEM images of carbon cloth supported $\mathrm{IrO}_{2}$ electrode in (a) low and (b) higher magnification 


\section{X-ray diffraction analysis}

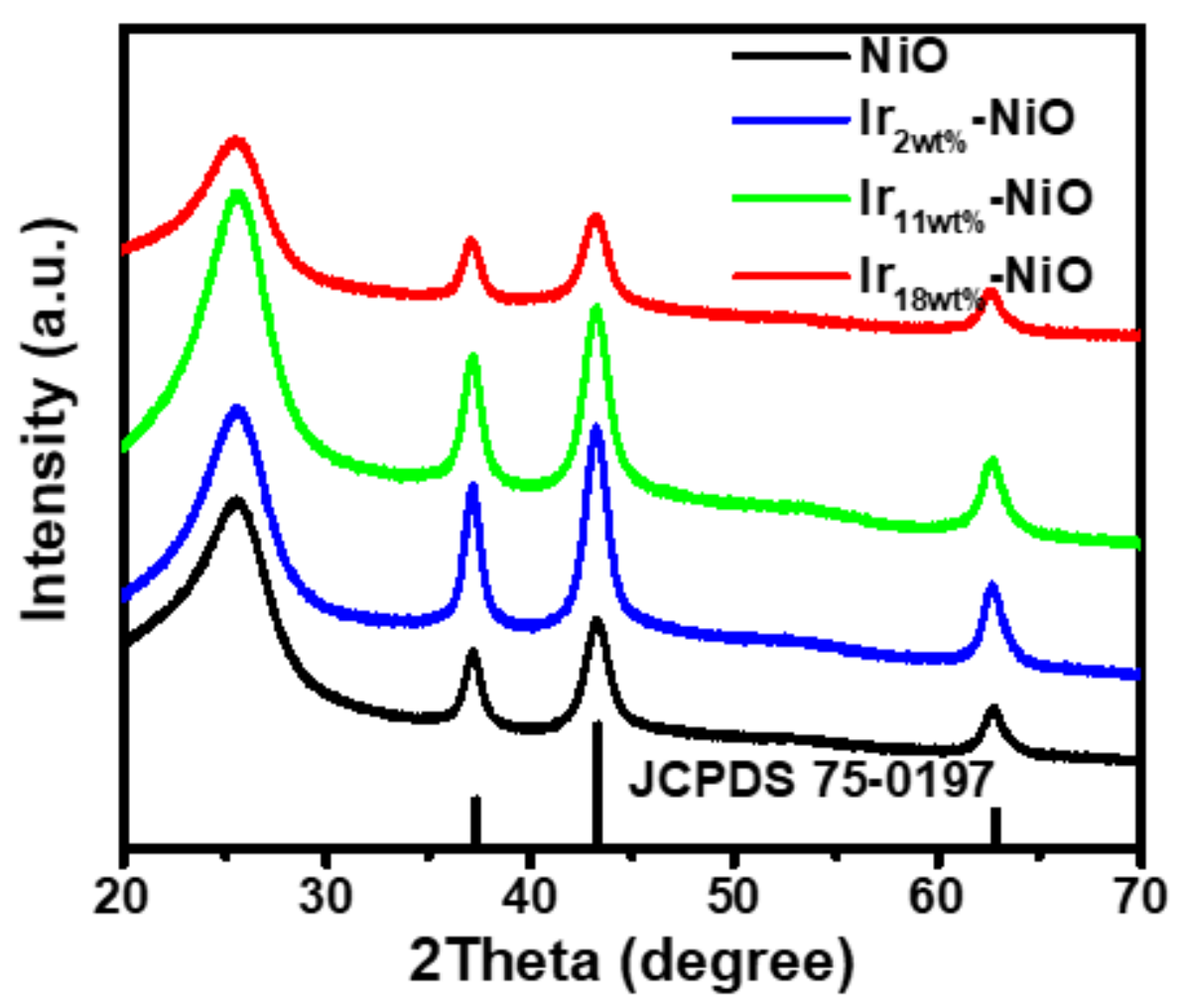

Figure S8 XRD patterns of different Ir loading amount $\mathrm{NiO}$ 


\section{X-ray photoelectron spectroscopy}
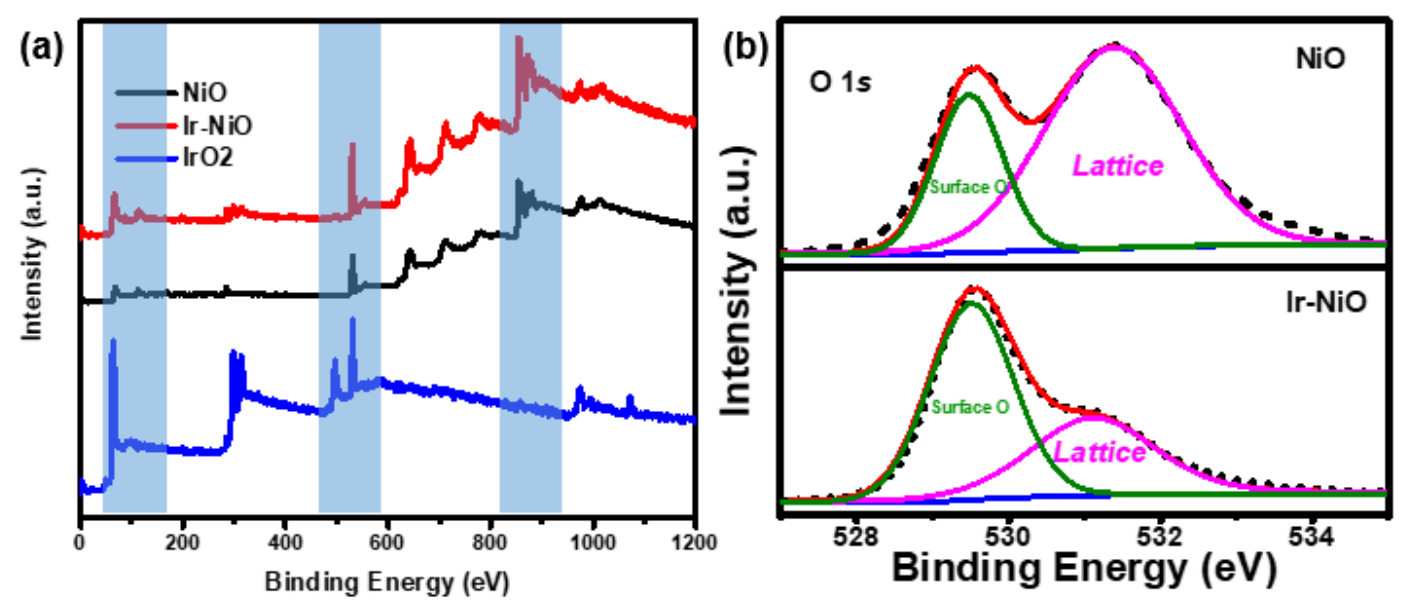

Figure S9 (a) XPS survey spectrum of $\mathrm{NiO}, \mathrm{IrO}_{2}$ and $\mathrm{Ir}-\mathrm{NiO}$, (b) Curve-resolved XPS of the $\mathrm{O} 1 \mathrm{~s}$ region for $\mathrm{NiO}$ and $\mathrm{Ir}-\mathrm{NiO}$ sample 


\section{X-ray absorption spectroscopy analysis}

\subsection{EXAFS at Ir $\mathrm{L3}$ edge on Ir foil and $\mathrm{IrO}_{2}$}

(a)

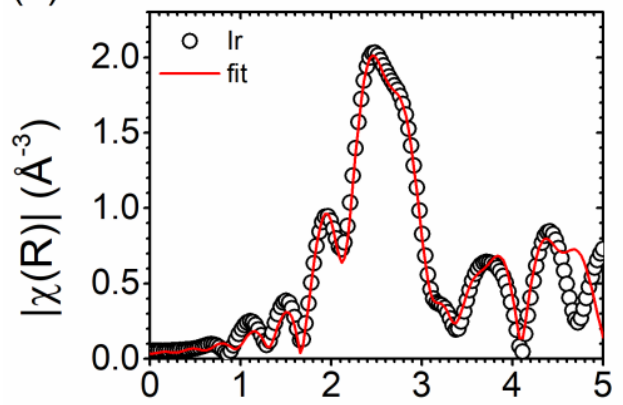

(c) Radial Distance $(\AA)$

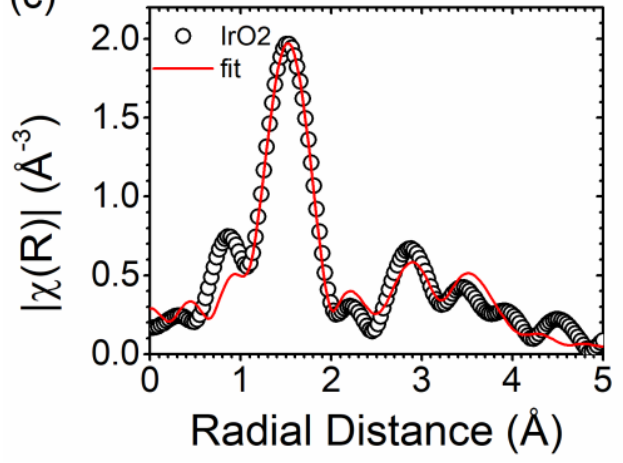

(b)
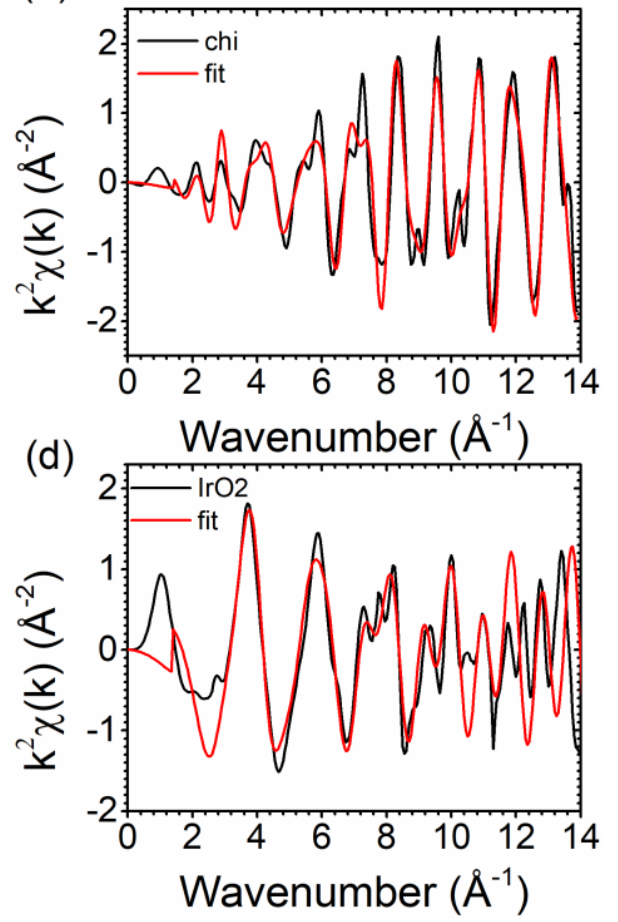

Figure S10. EXAFS data and fit for Ir in (a) R-space and (b) k-space, and for $\mathrm{IrO}_{2}$ in (c) R-space and (d) k-space. The black dots and black lines are data and the red lines are fits.

Table S1 Quantitative information of of EXAFS fits Ir and $\mathrm{IrO}_{2}$ reference samples (Figure S10)

\begin{tabular}{|c|c|c|c|c|c|}
\hline & Scattering Path & $\mathrm{CN}$ & $\mathrm{R}$ & $\mathrm{E}_{0}$ & $\sigma^{2}$ \\
\hline \multirow{3}{*}{ Ir } & Ir-Ir & 12 & $2.71(1)$ & $7.9(7)$ & $0.0029(5)$ \\
\hline & Ir-Ir & 6 & $3.83(1)$ & $7.9(7)$ & $0.0044(6)$ \\
\hline & Ir-Ir & 24 & $4.69(1)$ & $7.9(7)$ & $0.0048(3)$ \\
\hline \multirow{4}{*}{$\mathrm{IrO}_{2}$} & Ir-O & 2 & $1.91(2)$ & 7.3(9) & $0.0099(4)$ \\
\hline & Ir-O & 4 & $1.95(2)$ & 7.3(9) & $0.0008(3)$ \\
\hline & Ir-O & 4 & $3.52(7)$ & 7.3(9) & $0.0006(2)$ \\
\hline & Ir-Ir & 8 & $3.51(2)$ & $7.3(9)$ & $0.0025(1)$ \\
\hline
\end{tabular}


- $\mathrm{CN}$ : coordination number

- The number in the bracket is the last digit errors.

- $\quad \mathrm{R}$ : scattering path distance (for single scattering, it can represent bond distance)

- $\quad$ The $\mathrm{CN}$ is calculated by $\mathrm{CN}^{*}$ amp(materials)/amp(standard)

\subsection{EXAFS at Ir $\mathrm{L}_{3}$ edge on Ir-NiO catalyst}
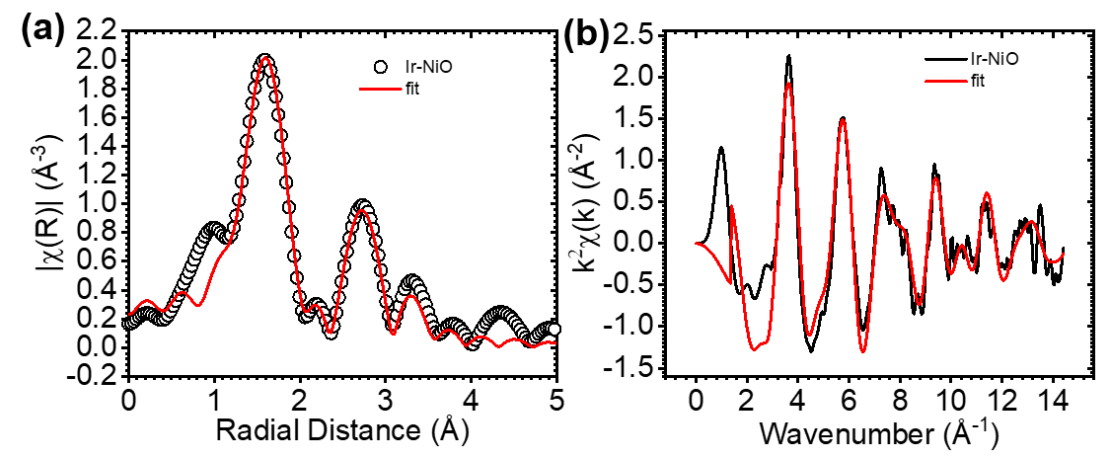

Figure S11 EXAFS data and fit for Ir-NiO in (a) R-space and (b) k-space, the black dots and black line are data and the red lines are fits.

Table S2 Quantitative information of the Ir L-edge EXAFS fits of Ir-NiO sample (Figure S11)

\begin{tabular}{|c|c|c|c|c|c|}
\hline & $\begin{array}{l}\text { Scattering } \\
\text { Path }\end{array}$ & $\mathrm{CN}$ & $\mathrm{R}$ & E0 & $\sigma 2$ \\
\hline \multirow{6}{*}{$\mathrm{Ir}-\mathrm{NiO}$} & Ir-O & $1.1(1)$ & $1.85(7)$ & $7.3(7)$ & $0.0013(9)$ \\
\hline & Ir-O & $4.2(1)$ & $2.00(6)$ & $7.3(7)$ & $0.0007(4)$ \\
\hline & Ir-O & $1.1(1)$ & $2.11(2)$ & $7.3(7)$ & $0.0062(9)$ \\
\hline & Ir-Ni & $4.2(1)$ & $2.93(6)$ & $7.3(7)$ & $0.0121(6)$ \\
\hline & Ir-Ni & $4.2(1)$ & $3.07(3)$ & $7.3(7)$ & $0.0060(7)$ \\
\hline & Ir-O & $4.2(1)$ & $3.66(5)$ & $7.3(7)$ & $0.0008(4)$ \\
\hline
\end{tabular}



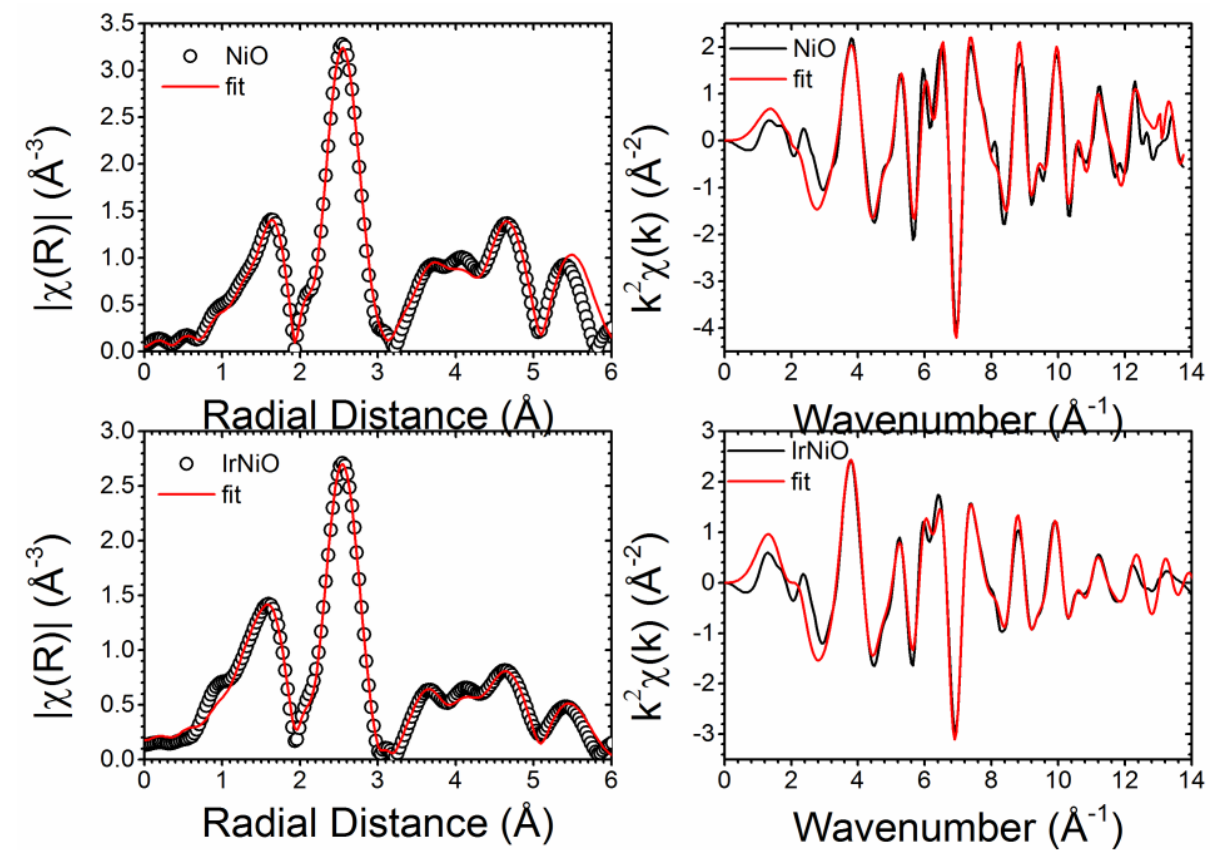

Figure S12 EXAFS data and fit for Ni in (a) R-space and (b) k-space, and for NiO in (c) R-space and (d) k-space for IrNiO. The black dots and black lines are data and the red lines are fits.

Table S3 Quantitative information of the Ni K-edge EXAFS fits (Figure S12)

\begin{tabular}{l|ccccc}
\hline \multirow{3}{*}{ Scattering Path } & $\mathrm{CN}$ & $\mathrm{R}$ & $\mathrm{E}_{0}$ & $\sigma^{2}$ \\
\hline & $\mathrm{Ni}-\mathrm{O}$ & $1.2(1)$ & $2.01(1)$ & $-3.1(8)$ & $0.0043(8)$ \\
$\mathrm{Ni}-\mathrm{O}$ & $6.0(5)$ & $2.10(1)$ & $-3.1(8)$ & $0.0109(9)$ \\
$\mathrm{Ni}-\mathrm{Ir}$ & $2.4(2)$ & $2.86(1)$ & $-3.1(8)$ & $0.0307(3)$ \\
& $\mathrm{Ni}-\mathrm{Ni}$ & $9.5(8)$ & $2.96(1)$ & $-3.1(8)$ & $0.0077(6)$ \\
& $\mathrm{Ni}-\mathrm{O}$ & $3.6(3)$ & $3.53(1)$ & $-3.1(8)$ & $0.0177(1)$ \\
& Ni-O-Ni & $38(3)$ & $3.58(1)$ & $-3.1(8)$ & $0.0035(8)$ \\
& Ni-Ni & $6.0(5)$ & $4.19(1)$ & $-3.1(8)$ & $0.0012(9)$ \\
& Ni-O-Ni & $12(1)$ & $4.19(1)$ & $-3.1(8)$ & $0.0113(1)$ \\
& Ni-O-Ni-O & $6.0(5)$ & $4.19(1)$ & $-3.1(8)$ & $0.0039(1)$ \\
& Ni-O & $19(2)$ & $4.69(1)$ & $-3.1(8)$ & $0.0106(8)$ \\
& Ni-O-Ni & $29(2)$ & $4.87(1)$ & $-3.1(8)$ & $0.0013(4)$ \\
& Ni-O-O & $38(3)$ & $4.87(1)$ & $-3.1(8)$ & $0.0143(3)$ \\
& Ni-Ni & $14(1)$ & $5.13(1)$ & $-3.1(8)$ & $0.0077(2)$ \\
& Ni-Ni & $19(2)$ & $5.93(1)$ & $-3.1(8)$ & $0.0122(1)$ \\
& Ni-Ni-Ni-Ni & $10(1)$ & $5.93(1)$ & $-3.1(8)$ & $0.0130(7)$ \\
\hline
\end{tabular}




\begin{tabular}{l|ccccc}
\hline & Scattering Path & $\mathrm{CN}$ & $\mathrm{R}$ & $\mathrm{E}_{0}$ & $\sigma^{2}$ \\
\hline \multirow{3}{*}{$\mathrm{Ni}$} & 6 & $2.09(1)$ & $-2.1(9)$ & $0.0061(7)$ \\
$\mathrm{NiO}$ & $\mathrm{Ni}-\mathrm{Ni}$ & 12 & $2.96(1)$ & $-2.1(9)$ & $0.0059(8)$ \\
$\mathrm{Ni}-\mathrm{O}-\mathrm{Ni}$ & 48 & $3.57(1)$ & $-2.1(9)$ & $0.0015(4)$ \\
$\mathrm{Ni}$ & 6 & $4.18(1)$ & $-2.1(9)$ & $0.0015(1)$ \\
& $\mathrm{Ni}-\mathrm{O}-\mathrm{Ni}$ & 12 & $4.18(1)$ & $-2.1(9)$ & $0.0072(2)$ \\
& $\mathrm{Ni}$ & 6 & $4.18(1)$ & $-2.1(9)$ & $0.0047(9)$ \\
& $\mathrm{Ni}-\mathrm{Ni}-\mathrm{O}$ & 24 & $4.68(1)$ & $-2.1(9)$ & $0.0057(8)$ \\
& Ni-O-Ni & 48 & $4.86(1)$ & $-2.1(9)$ & $0.0044(6)$ \\
& Ni-O-O & 48 & $4.86(1)$ & $-2.1(9)$ & $0.0036(3)$ \\
& Ni-Ni & 24 & $5.12(1)$ & $-2.1(9)$ & $0.0050(6)$ \\
& Ni-O-Ni & 48 & $5.42(1)$ & $-2.1(9)$ & $0.0008(4)$ \\
& Ni-Ni & 24 & $5.91(1)$ & $-2.1(9)$ & $0.0070(9)$ \\
& Ni-Ni-Ni-Ni & 12 & $5.91(1)$ & $-2.1(9)$ & $0.0071(3)$ \\
\hline
\end{tabular}




\section{Comparison of OER activity with recent literature}

Table S4 Comparison of OER activity for high-performance electrocatalysts in alkaline $1 \mathrm{M} \mathrm{KOH}$ from recent literatures.

\begin{tabular}{|c|c|c|c|c|}
\hline Catalyst & $\begin{array}{c}\eta \text { vs. RHE (mV)@ } \\
\mathrm{j}=10 \mathrm{~mA} \mathrm{~cm}^{-2}\end{array}$ & $\begin{array}{c}\eta \text { vs. RHE (mV) } \\
@ j=100 \mathrm{~mA} \mathrm{~cm}^{-2}\end{array}$ & $\begin{array}{l}\text { Tafel Slope } \\
\left(\mathrm{mV} \text { dec }^{-1}\right)\end{array}$ & $\begin{array}{c}\text { Reference } \\
\text { (journal,year) }\end{array}$ \\
\hline Ir-NiO & 215 & 260 & 38 & this work \\
\hline $\mathrm{w}-\mathrm{Ni}(\mathrm{OH})_{2}$ & 237 & 280 & 33 & 2 (Nat. com., 2019) \\
\hline Mn/Fe-HIB-MOF & 280 & & 45 & $\begin{array}{c}3 \text { (Energy Environ. Sci. } \\
\text { 2019) }\end{array}$ \\
\hline $\mathrm{MoS}_{2} / \mathbf{N i S}_{\mathbf{2}}$ & 278 & 394 & 91.7 & ${ }^{4}$ (Adv. Sci., 2019) \\
\hline $\mathrm{D}-\mathrm{U}-\mathrm{Co}(\mathrm{OH})_{2}$ & 223 & & 131 & $\begin{array}{c}\text { 5(ACS Energy Lett. } \\
\text { 2018) }\end{array}$ \\
\hline $\mathbf{Y}_{2} \mathrm{Ru}_{2}-\mathrm{x} \mathrm{Co}_{\mathrm{x}} \mathrm{O}_{7}$ & 260 & & 34 & '(Adv. Mater., 2019) \\
\hline $\mathrm{CoOOH}$ & 253 & & 87 & $\begin{array}{c}{ }^{7} \text { (Energy Environ. } \\
\text { Sci., 2019) } \\
\end{array}$ \\
\hline $\mathrm{Zn}_{0.2} \mathrm{Co}_{0.8} \mathrm{OOH}$ & 235 & & 34.7 & ${ }^{8}$ (Nat. Energy, 2019) \\
\hline Ni-MOFs & 265 & & 54 & $\begin{array}{c}\text { 9(Energy Environ. Sci., } \\
\text { 2018) }\end{array}$ \\
\hline $\mathrm{CoFe}_{0.25} \mathrm{Al}_{1.75} \mathrm{O}_{4}$ & 291 & & & ${ }^{10}$ (Nat. Catal. 2019) \\
\hline $\mathrm{NiN}_{4} \mathrm{C}_{4}$ & 331 & & 64 & ${ }^{11}$ (Nat. Catal. 2018) \\
\hline Ni-O-G SACs & 224 & 390 & 42 & ${ }^{12}$ (Adv. Sci. 2020) \\
\hline NiO/NiFe LDH & 215 & 280 & 30 & ${ }^{13}$ (Adv. Mater., 2019) \\
\hline $\mathrm{Au} / \mathrm{NiFe}$ & 237 & & 36 & $\begin{array}{c}{ }^{14} \text { (J. Am. Chem. Soc. } \\
\text { 2018) } \\
\end{array}$ \\
\hline $\mathrm{AC}-\mathrm{Co}_{2}(\mathrm{OH})_{3} \mathrm{Cl}$ & 270 & & 42 & ${ }^{15}$ (Adv. Mater., 2019) \\
\hline
\end{tabular}




\section{Electrochemical evaluation of ECSA and other metal-NiO catalyst}
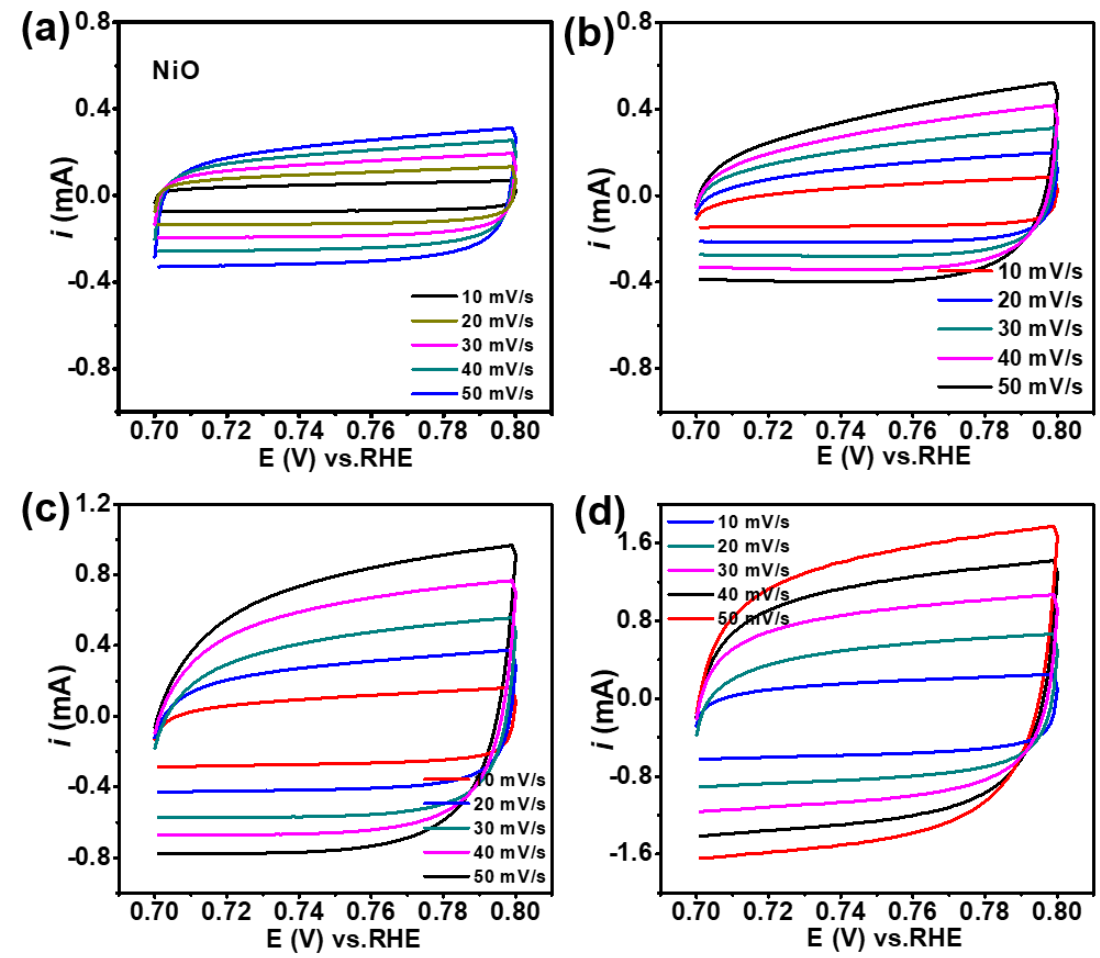

Figure S13 Cyclic voltammograms of (a) pure $\mathrm{NiO}$, (b) $\mathrm{Ir}_{2 \mathrm{wt} \%}-\mathrm{NiO}$, (c) $\operatorname{Ir}_{11 \mathrm{wt} \%}-\mathrm{NiO}$ and (d) $\operatorname{Ir}_{18 \mathrm{wt} \%}-$ $\mathrm{NiO}$ with various scan rates in $1 \mathrm{M} \mathrm{KOH}$.
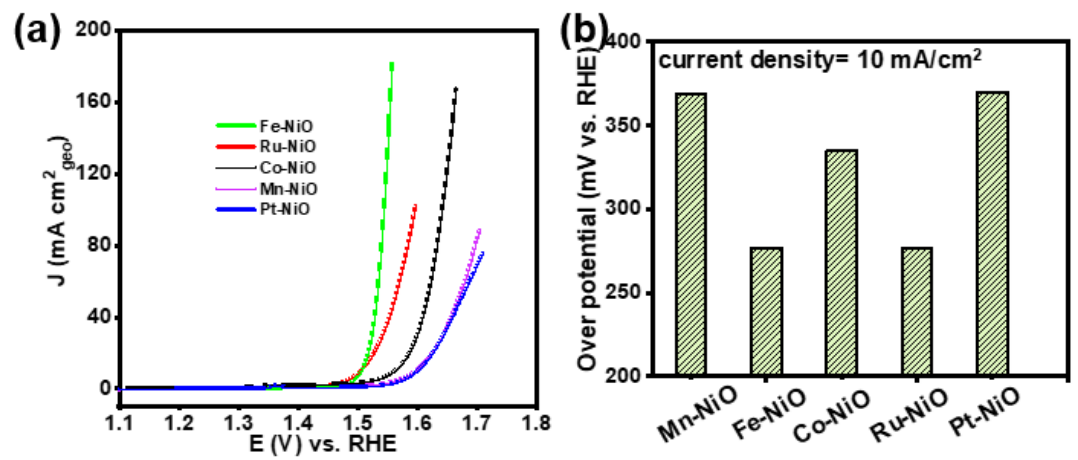

Figure S14 (a) Polarization curves for OER on Mn-NiO, Fe-NiO, Co-NiO, Ru-NiO and Pt$\mathrm{NiO}$ catalyst in $1 \mathrm{M} \mathrm{KOH}$. (b) corresponding overpotential of different catalyst at current density of $10 \mathrm{~mA} \mathrm{~cm}^{-2}$. 


\section{Growth process}
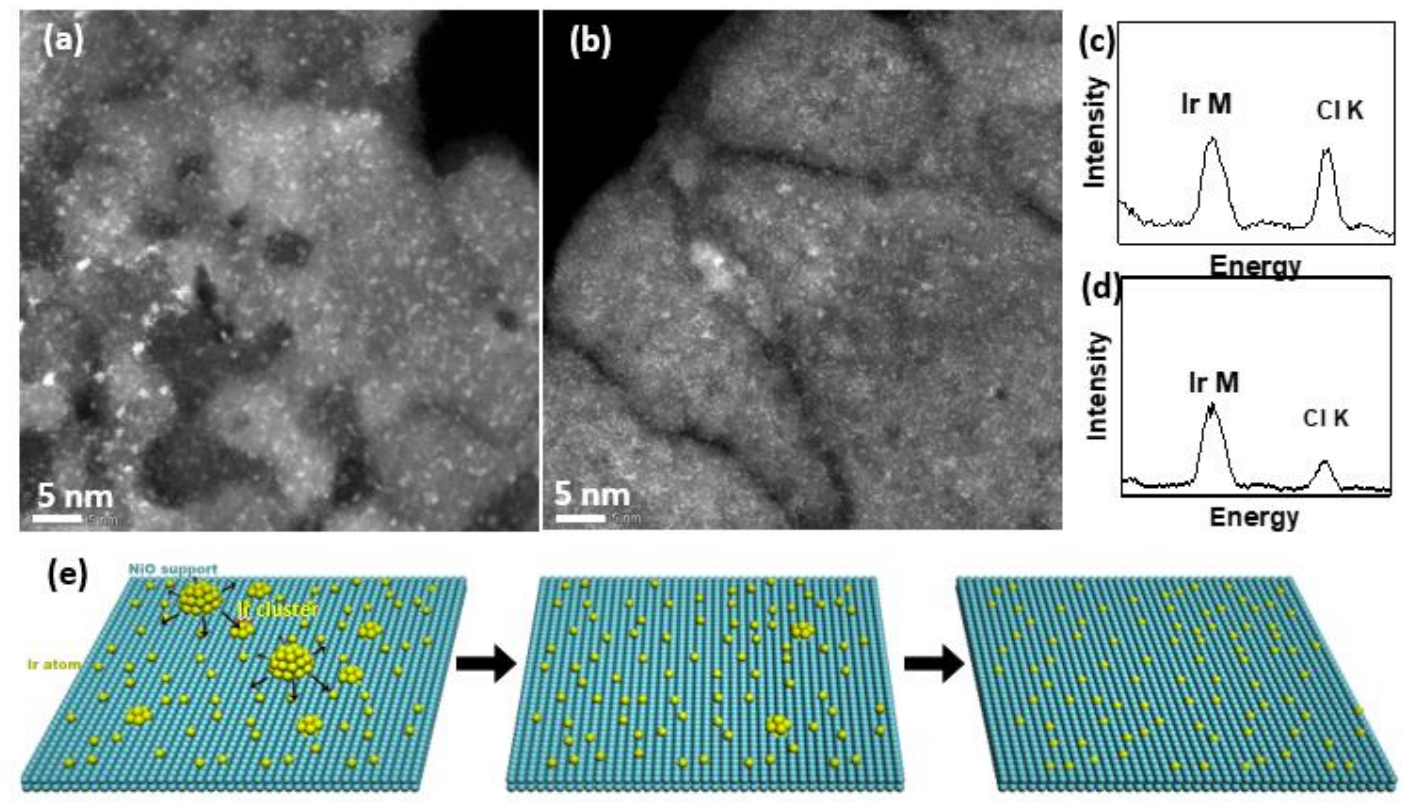

Figure S15 (a-b) different growth stage during formation of isolated IrOx species. (a) $1 \mathrm{~min}$ at $350^{\circ} \mathrm{C}$ and (b) $1 \mathrm{~h}$ at $350^{\circ} \mathrm{C}$. (c) EDS spectrum for Ir and $\mathrm{Cl}$ of (a) and (d) EDS spectrum of (b). (e) growth scheme of isolated $\mathrm{IrO}_{\mathrm{x}}$ species on $\mathrm{NiO}$ support.

To elucidate the formation pathway of the Ir-NiO, we collected the intermediate products at two different time slots into a standard synthesis and conducted STEM analysis. At $\mathrm{t}=1 \mathrm{~min}$ after heated to $350^{\circ} \mathrm{C}$, The anchored species were dominated by Ir species cluster (Figure S15a). The EDS spectrum in Figure $\mathrm{S} 15 \mathrm{c}$ indicates a high $\mathrm{Cl}$ residual. When reaction time extent to 1h (Figure 15b), most clusters divided into single atom. The $\mathrm{Cl}$ content in this stage reduced as well. Figure S15e depicts the evolution process. 


\section{Computational framework}

\subsection{Calculation details}

Density functional theory (DFT) calculations are performed using generalized gradient approximation (GGA) in the form of Perdew-Burke-Ernzerhof (PBE) for the exchange-correlation potentials, ${ }^{16}$ the projector augmented wave method, ${ }^{17}$ and a plane-wave basis set of $450 \mathrm{eV}$, as implemented in the Vienna ab initio simulation package (VASP) with consideration of spinpolarization. ${ }^{18-19}$ We apply a Hubbard- $\mathrm{U}$ correction of $\mathrm{U}=6.45 \mathrm{eV}$ to the d-electrons of $\mathrm{Ni}$ to account for the on-site correlation effects. ${ }^{20-21}$ The optimized lattice constants of $\mathrm{NiO}$ (rock-salt) and $\mathrm{IrO}_{2}$ (rutile) are $\mathrm{a}=4.180 \AA$, and $\mathrm{a}=4.564 \AA, \mathrm{c}=3.200 \AA$, respectively, which are well consistent with the previous theoretical studies ${ }^{20,22}$ as well as with the experimental results. ${ }^{23-24}$ The oxygen evolution reaction (OER) on the surfaces of $\mathrm{NiO}(001)$ and $\mathrm{IrO}_{2}(110)$ are carried out using the slab models composed of $\mathrm{p}(2 \times 2)$ and $\mathrm{p}(2 \times 1)$ supercells with four and twelve atomic monolayers, respectively. The vacuum layers of these slab models are set to $\sim 15 \AA$. The surface Brillouin-zone of $\mathrm{NiO}(001)$ $\mathrm{p}(2 \times 2)$ and $\mathrm{IrO}_{2}(110)-\mathrm{p}(2 \times 1)$ are sampled with Gamma centered k-meshes of $4 \times 4 \times 1$ and $4 \times 4 \times 1$, respectively. The bottom two atomic monolayers of $\mathrm{NiO}(001)$ and three atomic monolayers of $\mathrm{IrO}_{2}(110)$ are fixed at their bulk positions while the rest atomic layers and adsorbates are free to move in all directions until the residual force on each atom is less than $0.05 \mathrm{eV} / \AA$. The climbingimage nudged elastic band (CI-NEB) method is applied to accurately locate the transition state with the force on each image converged to less than $0.05 \mathrm{eV} / \AA .{ }^{25}$ Dipole corrections are taken into account throughout the calculations.

\subsection{Free energy diagram}

We consider the OER that follows the four-electron mechanism, ${ }^{26}$ which involves four reaction steps

$$
\begin{aligned}
& \mathrm{H}_{2} \mathrm{O}_{(\mathrm{l})} \rightarrow \mathrm{OH}^{*}+\mathrm{H}^{+}+\mathrm{e}^{-} \\
& \mathrm{OH}^{*} \rightarrow \mathrm{O}^{*}+\mathrm{H}^{+}+\mathrm{e}^{-} \\
& \mathrm{O}^{*}+\mathrm{H}_{2} \mathrm{O}_{(\mathrm{l})} \rightarrow \mathrm{OOH}^{*}+\mathrm{H}^{+}+\mathrm{e}^{-} \\
& \mathrm{OOH}^{*} \rightarrow *+\mathrm{O}_{2(\mathrm{~g})}+\mathrm{H}^{+}+\mathrm{e}^{-}
\end{aligned}
$$

The asterisk $(*)$ represents the active site of catalysts. 
The free energies of reactant, product, and reaction intermediates are defined as

$$
\mathrm{G}=\mathrm{E}_{\mathrm{DFT}}+\mathrm{E}_{\mathrm{ZPE}}-\mathrm{TS}
$$

where $\mathrm{E}_{\mathrm{DFT}}, \mathrm{E}_{\mathrm{ZPE}}$, and TS represent DFT-calculated electronic energy, zero-point energy, and entropy of the system. The $\mathrm{E}_{\mathrm{ZPE}}$ and TS of gas-phase molecules and reaction intermediates are listed in Table S5. For the reaction step containing the coupled proton-electron pair, the free energy of a pair of proton and electron $\left(\mathrm{H}^{+}+\mathrm{e}^{-}\right)$is calculated as a function of applied potential relative to reversible hydrogen electrode, i.e., $\mu\left(\mathrm{H}^{+}\right)+\mu\left(\mathrm{e}^{-}\right)=\frac{1}{2} \mu\left(\mathrm{H}_{2}\right)-\mathrm{eU}$, according to the computational hydrogen electrode (CHE) model. ${ }^{27}$ The potential determining step (pds) is defined as the last step to become downhill in free energy with the increase of potential.

Table S5. Zero-point energy (ZPE) and entropy corrections used to calculate the free energies of reactant, product, and reaction intermediates of OER.

\begin{tabular}{|l|c|c|c|}
\hline & ZPE $(\mathbf{e V})$ & $\mathbf{T S}(\mathbf{e V})(\mathbf{T}=\mathbf{2 9 8 . 1 5 K})$ & $\Delta \mathbf{G}_{\text {corr }}(\mathbf{e V})$ \\
\hline $\mathbf{H}_{2} \mathbf{O}$ & 0.57 & $0.67(0.035$ bar $)$ & -0.10 \\
\hline $\mathbf{H}_{2}$ & 0.27 & 0.40 & -0.13 \\
\hline *OH & 0.34 & 0 & 0.34 \\
\hline *O & 0.07 & 0 & 0.07 \\
\hline *OOH & 0.43 & 0 & 0.43 \\
\hline
\end{tabular}


(a)

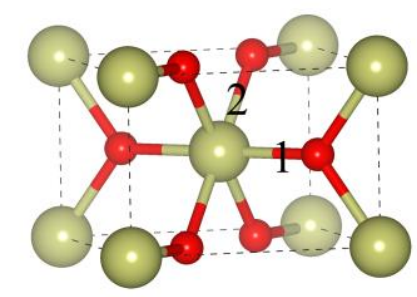

bond $_{1}=1.99 \AA$

bond $_{2}=2.02 \AA$

$\mathrm{avg}=2.01 \AA$ (b)

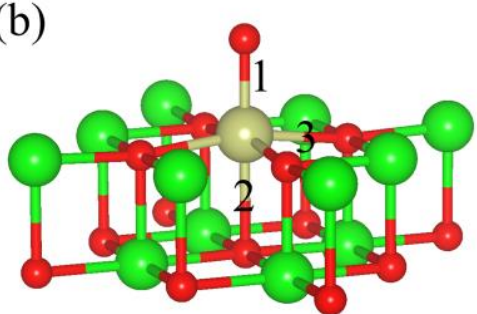

bond $_{1}=1.82 \AA$

bond $_{2}=2.28 \AA$

bond $_{3}=2.12 \AA$

$\mathrm{avg}=2.10 \AA$

Figure S16. The local octahedral environment of $\mathrm{Ir}$ atom in (a) bulk $\mathrm{IrO}_{2}$ and (b) on the $\mathrm{Ir}-\mathrm{NiO}(001)$ surface with one chemisorbed $\mathrm{O}^{*}$ species on Ir atom. The bond lengths of Ir-O as well as the average value are compiled below each configuration.

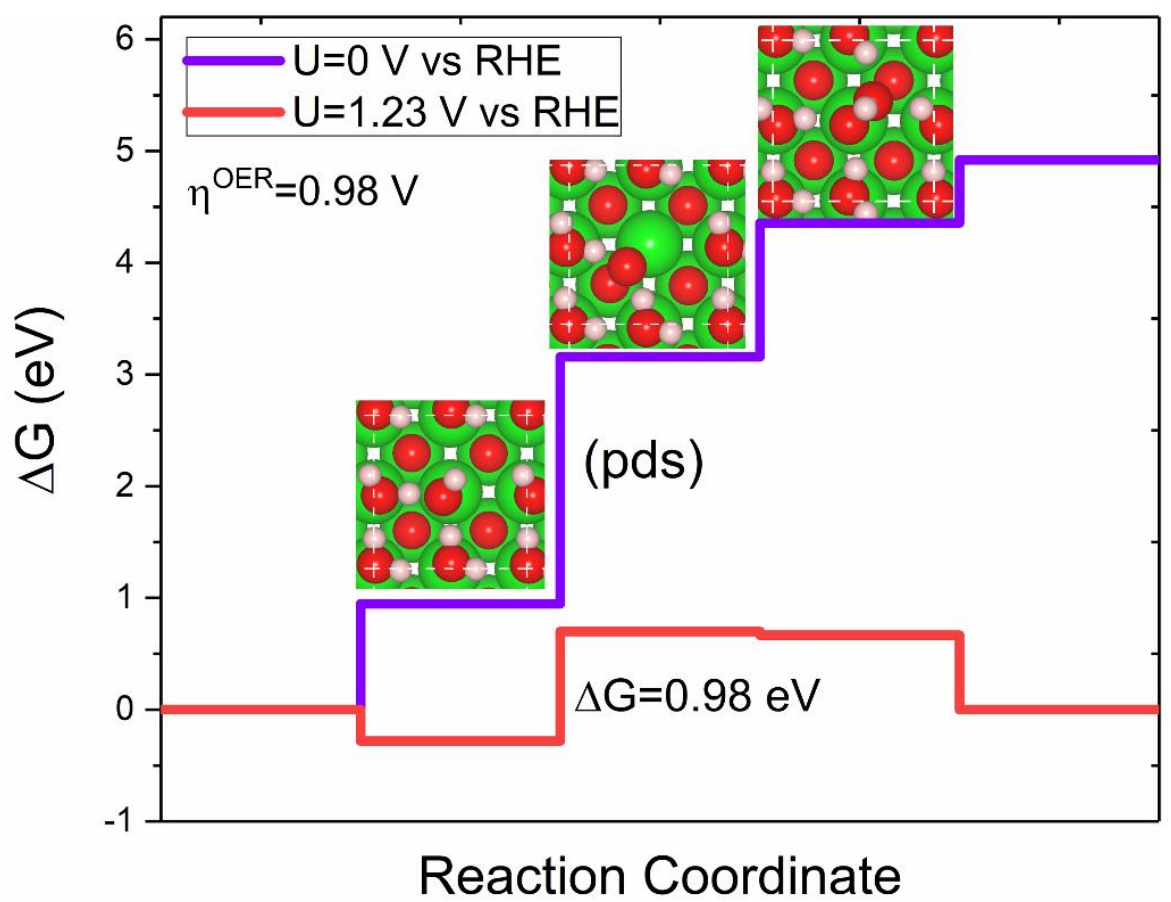

Figure S17. Free energy diagram of OER on the perfect $\mathrm{NiO}(001)$ surface. 


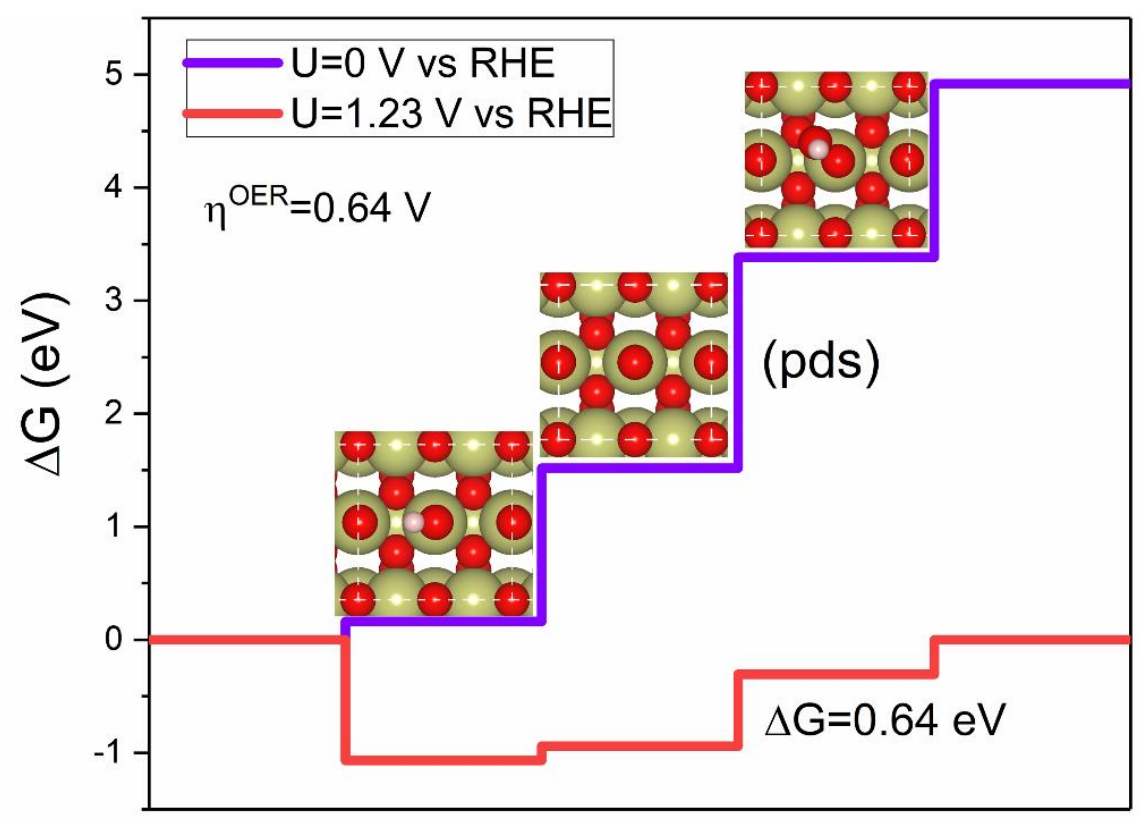

Reaction Coordinate

Figure S18. Free energy diagram of OER on the $\mathrm{IrO}_{2}(110)$ surface. 


\section{Reference}

1. Louie, M. W.; Bell, A. T., An investigation of thin-film Ni-Fe oxide catalysts for the electrochemical evolution of oxygen. Journal of the American Chemical Society 2013, 135 (33), 12329-12337.

2. Yan, J.; Kong, L.; Ji, Y.; White, J.; Li, Y.; Zhang, J.; An, P.; Liu, S.; Lee, S.-T.; Ma, T., Single atom tungsten doped ultrathin $\alpha-\mathrm{Ni}(\mathrm{OH}) 2$ for enhanced electrocatalytic water oxidation. Nature Communications 2019, 10 (1), 2149.

3. Shinde, S. S.; Lee, C. H.; Jung, J.-Y.; Wagh, N. K.; Kim, S.-H.; Kim, D.-H.; Lin, C.; Lee, S. U.; Lee, J.-H., Unveiling dual-linkage 3D hexaiminobenzene metal-organic frameworks towards long-lasting advanced reversible Zn-air batteries. Energy \& Environmental Science 2019, 12 (2), 727-738.

4. Lin, J.; Wang, P.; Wang, H.; Li, C.; Si, X.; Qi, J.; Cao, J.; Zhong, Z.; Fei, W.; Feng, J. J. A. S., Defect-Rich Heterogeneous MoS2/NiS2 Nanosheets Electrocatalysts for Efficient Overall Water Splitting. 2019, 1900246.

5. Zhang, B.; Qi, Z.; Wu, Z.; Lui, Y. H.; Kim, T.-H.; Tang, X.; Zhou, L.; Huang, W.; Hu, S. J. A. E. L., DefectRich 2D Material Networks for Advanced Oxygen Evolution Catalysts. 2018, 4 (1), 328-336.

6. Kim, M.; Lee, B.; Ju, H.; Lee, S. W.; Kim, J. J. A. M., Reducing the Barrier Energy of Self Reconstruction for Anchored Cobalt Nanoparticles as Highly Active Oxygen Evolution Electrocatalyst. 2019, 1901977.

7. Zhou, J.; Wang, Y.; Su, X.; Gu, S.; Liu, R.; Huang, Y.; Yan, S.; Li, J.; Zhang, S. J. E.; Science, E., Electrochemically accessing ultrathin Co (oxy)-hydroxide nanosheets and operando identifying their active phase for the oxygen evolution reaction. 2019, 12 (2), 739-746.

8. Huang, Z.-F.; Song, J.; Du, Y.; Xi, S.; Dou, S.; Nsanzimana, J. M. V.; Wang, C.; Xu, Z. J.; Wang, X., Chemical and structural origin of lattice oxygen oxidation in Co-Zn oxyhydroxide oxygen evolution electrocatalysts. Nature Energy 2019, 4 (4), 329-338.

9. Sun, H.; Lian, Y.; Yang, C.; Xiong, L.; Qi, P.; Mu, Q.; Zhao, X.; Guo, J.; Deng, Z.; Peng, Y. J. E.; Science, E., A hierarchical nickel-carbon structure templated by metal-organic frameworks for efficient overall water splitting. 2018, 11 (9), 2363-2371.

10. Wu, T.; Sun, S.; Song, J.; Xi, S.; Du, Y.; Chen, B.; Sasangka, W. A.; Liao, H.; Gan, C. L.; Scherer, G. G.; Zeng, L.; Wang, H.; Li, H.; Grimaud, A.; Xu, Z. J., Iron-facilitated dynamic active-site generation on spinel CoAl2O4 with self-termination of surface reconstruction for water oxidation. Nature Catalysis 2019.

11. Fei, H.; Dong, J.; Feng, Y.; Allen, C. S.; Wan, C.; Volosskiy, B.; Li, M.; Zhao, Z.; Wang, Y.; Sun, H., General synthesis and definitive structural identification of MN 4 C 4 single-atom catalysts with tunable electrocatalytic activities. Nature Catalysis 2018, 1 (1), 63-72.

12. Li, Y.; Wu, Z. S.; Lu, P.; Wang, X.; Liu, W.; Liu, Z.; Ma, J.; Ren, W.; Jiang, Z.; Bao, X., High-Valence Nickel Single - Atom Catalysts Coordinated to Oxygen Sites for Extraordinarily Activating Oxygen Evolution Reaction. Advanced Science 2020, 1903089.

13. Gao, Z. W.; Liu, J. Y.; Chen, X. M.; Zheng, X. L.; Mao, J.; Liu, H.; Ma, T.; Li, L.; Wang, W. C.; Du, X. W., Engineering $\mathrm{NiO} / \mathrm{NiFe} \mathrm{LDH}$ intersection to bypass scaling relationship for oxygen evolution reaction via dynamic tridimensional adsorption of intermediates. Advanced Materials 2019, 31 (11), 1804769.

14. Zhang, J.; Liu, J.; Xi, L.; Yu, Y.; Chen, N.; Sun, S.; Wang, W.; Lange, K. M.; Zhang, B., Single-atom $\mathrm{Au} / \mathrm{NiFe}$ layered double hydroxide electrocatalyst: probing the origin of activity for oxygen evolution reaction. Journal of the American Chemical Society 2018, 140 (11), 3876-3879.

15. Jiang, H.; He, Q.; Li, X.; Su, X.; Zhang, Y.; Chen, S.; Zhang, S.; Zhang, G.; Jiang, J.; Luo, Y., Tracking 
Structural Self-Reconstruction and Identifying True Active Sites toward Cobalt Oxychloride Precatalyst of Oxygen Evolution Reaction. Advanced Materials 2019, 31 (8), 1805127.

16. Perdew, J. P.; Ernzerhof, M.; Burke, K., Rationale for Mixing Exact Exchange with Density Functional Approximations. J Chem Phys 1996, 105 (105), 9982-9985.

17. Kresse, G.; Joubert, D., From ultrasoft pseudopotentials to the projector augmented-wave method. Phys Rev B 1999, 59 (3), 1758-1775.

18. Kresse, G.; Furthmüller, J., Efficient iterative schemes for ab initio total-energy calculations using a plane-wave basis set. Phys Rev B 1996, 54 (16), 11169-11186.

19. Kresse, G.; Furthmüller, J., Efficiency of ab-initio total energy calculations for metals and semiconductors using a plane-wave basis set. Comp Mater Sci 1996, 6 (1), 15-50.

20. Zhao, W.; Bajdich, M.; Carey, S.; Vojvodic, A.; Nørskov, J. K.; Campbell, C. T., Water Dissociative Adsorption on $\mathrm{NiO}(111)$ : Energetics and Structure of the Hydroxylated Surface. ACS Catal 2016, 6 (11), 7377-7384.

21. Wang, L.; Maxisch, T.; Ceder, G., Oxidation energies of transition metal oxides within the GGA+U framework. Phys Rev B 2006, 73 (19), 195107.

22. Gauthier, J. A.; Dickens, C. F.; Chen, L. D.; Doyle, A. D.; Nørskov, J. K., Solvation Effects for Oxygen Evolution Reaction Catalysis on IrO2(110). The Journal of Physical Chemistry C 2017, 121 (21), 1145511463.

23. Fievet, F.; Germi, P.; de Bergevin, F.; Figlarz, M., Lattice parameter, microstrains and nonstoichiometry in NiO. Comparison between mosaic microcrystals and quasi-perfect single microcrystals. J Appl Crystallogr 1979, 12 (4), 387-394.

24. Bolzan, A. A.; Fong, C.; Kennedy, B. J.; Howard, C. J., Structural Studies of Rutile-Type Metal Dioxides. Acta Cryst 1997, 53 (3), 373-380.

25. Henkelman, G.; Uberuaga, B. P.; Jónsson, H., A climbing image nudged elastic band method for finding saddle points and minimum energy paths. J Chem Phys 2000, 113 (22), 9901-9904.

26. Man, I. C.; Su, H.-Y.; Calle-Vallejo, F.; Hansen, H. A.; Martínez, J. I.; Inoglu, N. G.; Kitchin, J.; Jaramillo, T. F.; Nørskov, J. K.; Rossmeisl, J., Universality in Oxygen Evolution Electrocatalysis on Oxide Surfaces. ChemCatChem 2011, 3 (7), 1159-1165.

27. Nørskov, J. K.; Rossmeisl, J.; Logadottir, A.; Lindqvist, L.; Kitchin, J. R.; Bligaard, T.; Jonsson, H., Origin of the overpotential for oxygen reduction at a fuel-cell cathode. The Journal of Physical Chemistry $B$ 2004, 108 (46), 17886-17892. 